\title{
Memória, cultura e poder na sociedade do esquecimento ${ }^{1}$
}

\section{Resumo}

$\mathrm{O}$ artigo discute a memória como matéria prima para a pesquisa em diversas áreas das ciências sociais. Mostra as várias formas de memória existentes e seus papéis nos embates que a vida em sociedade ensejar.

Apresenta as principais características do processo de rememorar, falando do poder que a função seletiva da memória representa. Coloca a importância que os idosos possuíam como guardióes da memória, papel hoje exercido de maneira profissional pelas instituições-memória.

Mostra a força dos meios de comunicação modernos na construção da memória coletiva de uma dada sociedade e os riscos que esse quarto poder apresenta ao se perder a capacidade crítica na elaboração da memória.

Conclui salientando a importância da existência de instituições-memória dentro do mundo acadêmico como uma garantia da elaboração de versões sobre o passado construído de forma científica e, portanto, mais livres de influências político-ideológicas.

\section{Abstract}

The article discusses memory as raw material for research in different areas of Social Sciences. It shows the different forms in which memory exists and their roles in the clashes that life in society offers.

It presents the main characteristics of the process of recollection, talking of the power that the selective function of the memory represents. It also shows the importance that aged people had as guardians of the memory, role that nowadays is performed professionally by memory institutions.

It shows the strength of the modern means of communication in the construction of the collective memory of a given society and the risks that this fourth power presents if we lose the capacity of critics in elaborating the memory.

The article concludes by showing the importance of the existence of the memory institutions in the academic world as a guaranty of the elaboration of versions about the past, built in a scientific manner and thus, free of political-ideological influences.

Memória é a capacidade humana de reter fatos e experiências do passado e retransmití-los às novas gerações através de diferentes suportes empíricos (voz, música, imagem, textos etc.). Existe uma memória individual que é aquela guardada por um indivíduo e se refere às suas próprias vivências e experiências, mas que contém também aspectos da memória do grupo social onde ele se formou, isto é, no qual esse indivíduo foi socializado.

Há também aquilo que denominamos de memória coletiva, que é aquela formada pelos fatos e aspectos julgados relevantes pelos grupos dominantes e que são guardados como memória oficial da sociedade mais ampla. ${ }^{2}$ Ela geralmente se expressa naquilo que chamamos de lugares da memória $^{3}$ que são os memoriais, monumentos,

\footnotetext{
* Professora do Departamento de Ciências Sociais Aplicadas à Educação da Faculdade de Educação da UNICAMP e Diretora do Centro de Memória da UNICAMP.

${ }^{1}$ Uma versão ampliada deste texto foi publicada na coletânea Arquivos Fontes e Novas Tecnologias: questões para a história da educação, organizada por Luciano Mendes de Faria Filho - Campinas - SP: Autores Associados. 2000.

${ }^{2}$ HALBWACHS, Maurice. A memória coletiva. S. Paulo: Vértice/ Revista dos Tribunais, 1990.

${ }^{3}$ NORA, Pierre. Les lieux de memoire. 1. La Republique. Paris: Gallimard, 1984.
} 
murais, arquivos, bibliotecas, hinos oficiais, quadros e obras literárias e artísticas que exprimem a versão consolidada de um passado coletivo de uma dada sociedade.

Como contrapartida, ou outro lado da moeda, existem as memórias subterrâneas ou marginais que correspondem a versões sobre o passado dos grupos dominados de uma dada sociedade. Estas memórias geralmente não estão monumentalizadas e nem gravadas em suportes concretos como textos, fotografias, CD roms, obras de arte e só se expressam quando conflitos sociais as evocam ou quando os pesquisadores que se utilizam do método biográfico ou da história oral ${ }^{4} \mathrm{criam}_{\text {as }}$ condições para que elas emerjam e possam então ser registradas e analisadas. Depois desse processo, elas passam então a fazer parte da memória coletiva de uma dada sociedade. Essas memórias subterrâneas geralmente se encontram muito bem guardadas no âmago de famílias ou grupos sociais dominados nos quais são cuidadosamente passadas, de geração a geração, através de relatos, músicas, quadras poéticas, ocasiões em que os membros do grupo se auxiliam mutuamente na tarefa de relembrar, cada um contribuindo com detalhes que detonam processos rememorativos dos outros participantes. É o que denominamos uma construção compartilhada da memória.

Há pesquisas mostrando que grupos populares de origem rural, quando enfrentando outras condições e ritmos de vida em habitat urbano, valem-se de estratégias que incorporam formas modernas de registro, como as audio-visuais, para documentar suas atividades culturais no intuito de retransmitir saberes e memórias tradicionais para as novas gerações. ${ }^{5}$

O outro lado da função de memorizar é a de esquecer. Uma não se dá sem que a outra esteja presente. Não podemos manter na nossa memória todas as experiências que vivenciamos ou das quais tomamos conhecimento num dia comum das nossas vidas. Assim somos obrigados a selecionar, para serem mantidas em nossa memória, aquelas informações que possuem significado para nossas futuras tomadas de decisão.

$\mathrm{Na}$ sociedade ocidental atual, o ritmo acelerado do trabalho urbano somado à facilidade e rapidez dos meios de comunicação (criadas pelos constantes avanços tecnológicos) colocam o homem comum frente a uma quantidade avassaladora de informações. Tais fatos criam para o homem de hoje quase a obrigação de consumir a informação de forma acrítica, sem maiores cuidados seletivos, perdendo-se portanto uma das mais importantes funções da memória humana a capacidade seletiva - que é o PODER de separar aquilo que deve ser preservado, como lembrança importante, daqueles fatos e vivências que podem e devem ser descartados. A perda do exercício desse poder de seleção nas sociedades atuais, constitui o fator fundamental para a formação do que os profissionais da informação chamam de sociedades do esquecimento ${ }^{6}$.

É verdade que nós não nos lembramos de tudo o que aconteceu ou que nos foi ensinado ao longo de nossa vida. Descartamos a maioria das experiências vivenciadas e só retemos aquelas que possuem significado, isto é, são funcionais para nossa existência futura. Iuri Lotman ${ }^{7}$, um semiólogo falecido na segunda metade dos anos 90, que viveu atrás da Cortina de Ferro (sendo por isso suas obras pouco conhecidas entre nós), já dizia que cultura é memória, pois é a cultura de uma sociedade que fornece os filtros através

\footnotetext{
${ }^{4}$ VON SIMSON, Olga. Os desafios contemporâneos da história oral. Campinas - Centro de Memória da Unicamp, 1997.

${ }^{5}$ Para conhecer melhor essa pesquisa ver: CASSIANO, Célia. Memórias itinerantes: um estudo sobre a recriação das Folias de Reis em Campinas. 1998. Dissertação (Mestrado em Multimeios) - Instituto de Artes, Universidade Estadual de Campinas, Campinas.

${ }^{6}$ BRITO, Marilza E. Memória e cultura. Centro de Memória da Eletricidade no Brasil. Rio de Janeiro, 1989. (Caderno da Memória da Eletricidade. n.1).

${ }^{7}$ Para maiores informaçôes sobre esse semíologo ver: FERREIRA, Jerusa Pires. Cultura é Memória. In: Revista da USP. São Paulo, 1995, n. 24, p.115-120.
} 
dos quais os indivíduos que nela vivem podem exercer o seu poder de seleção, realizando as escolhas que determinam aquilo que será descartado e aquilo que precisa ser guardado ou retido pela memória, porque, sendo operacional, poderá servir como experiência válida ou informação importante para decisões futuras.

Nas sociedades da memória, que existiram no passado e ainda subsistem em locais isolados da África, da Oceania e da América do Sul, e nas quais o volume de informação é consideravelmente muito mais restrito, a memória é organizada e retida pelo conjunto de seus membros, os quais se incumbem também de transmiti-la às novas gerações, cabendo aos mais velhos, devido a sua maior experiência e vivência, o importante papel social de guardiões da memória. Cabe a eles a função de transmitir às novas gerações de seu grupo social os fatos e vivências que foram retidos como fundamentais para a sobrevivência do grupo.

Esse papel social dos idosos foi sendo gradativamente perdido ao longo da história das sociedades ocidentais, ${ }^{8}$ mas, muito mais intensamente, na contemporaneidade, quando cada vez mais se diversificam e se sofisticam os suportes para o registro e manutenção da memória (documentos escritos, imprensa, fotografia, vídeo, discos, CDs, DVDs, disquetes etc.). Esse enorme volume de informações fez surgir, nessas novas sociedades do esquecimento, instituições especialmente voltadas ao trabalho de coleta, seleção, organização, guarda, manutenção adequada e divulgação da memória de grupos sociais ou da sociedade em geral nessas novas sociedades do esquecimento.

Essas instituições realizam, portanto, hoje, de forma profissional, uma tarefa social anteriormente exercida pelos idosos. São elas os museus, arquivos, bibliotecas e centros de memória que, segundo critérios previamente estabelecidos, realizam o trabalho de coletar, tratar, recuperar, or- ganizar e colocar à disposição da sociedade a memória de uma região específica ou de um grupo social, memória essa retida em suportes materiais diversos.

Eixos definidos de pesquisa devem orientar esse trabalho, para que ele possa ser bem realizado e sua fixação se dê em suportes tecnicamente escolhidos. Os eixos que orientam o trabalho variam de instituição para instituição e representam o âmago do exercício de poder, por corresponderem aos objetivos do grupo que as criou e dirige.

Hoje, neste novo século, temos vivenciado, acompanhando um movimento geral da sociedade ocidental, uma forte necessidade de lembrar, como a outra face da moeda dos processos de mundialização. Quando se vive de maneira tão acelerada a ponto de sermos impedidos até de "sentir o tempo passar", como se diz popularmente, projetos envolvendo a memória possibilitam aos participantes dos mesmos habitar esse tempo e vivê-lo plenamente, numa relação que pode ser criativa e transformadora. Nesses projetos, os idosos certamente têm novamente um papel social definido e importante.

Ecléa Bosi em Memória e Sociedade: lembranças de velhos ${ }^{9}$, obra precursora no Brasil dos trabalhos científicos que incorporam como fonte de dados para a pesquisa o ato de lembrar, já observava que a memória não é sonho, mas trabalho. Podemos acrescentar que o ato de relembrar em conjunto, isto é, o ato de reconstruir a memória de forma compartilhada, é um trabalho que constrói sólidas pontes de relacionamento entre os indivíduos - porque alicerçadas numa bagagem cultural comum - e, talvez por isso, conduza à ação. Portanto, a memória compartilhada é tanto forma de domar o tempo, vivendo-o plenamente, como empuxo que nos leva à ação, constituindo uma estratégia muito valiosa nestes tempos em que tudo é transformado em mercadoria e tudo possui

\footnotetext{
${ }^{8}$ GIGLIO, Zula; VON SIMSON, Olga. A arte de recriar o passado: história oral e velhice bem sucedida. In: NERI, Anita L. Desenvolvimento e envelhecimento: perspectivas biológicas, psicológicas e sociológicas. Campinas, São Paulo: Papirus, 2001.

${ }^{9}$ BOSI, Ecléa. Memória e sociedade: lembranças de velhos. São Paulo: T.A. Queiroz, 1979.
} 
valor de troca. Essa memória compartilhada, ${ }^{10}$ enquanto desejo latente do homem pós-moderno, que se realiza numa relação não inserida na lógica de mercado, nos leva a construir redes de relacionamentos nas quais é possível focalizar em conjunto aspectos do passado, envolvendo participantes de diferentes gerações de um mesmo grupo social. Nesse processo são utilizados o que chamamos de "óculos do presente", para reconstruir vivências e experiências pretéritas, o que nos propicia melhor compreender os problemas do presente e pensar em bases mais sólidas e realistas nossas futuras ações.

Assim podemos perceber que o trabalho com a memória, no qual os velhos têm papel fundamental, mas os mais jovens também estão presentes, não nos aprisiona no passado, mas nos conduz com muito maior segurança para o enfrentamento dos problemas atuais, ao permitir a reconstrução de aspectos desse passado recente. O trabalho com a memória também possibilita uma transformação da consciência das pessoas nele direta ou indiretamente envolvidas, no que concerne à própria documentação histórica, (ampliando essa noção que abarca agora os mais diversos suportes: textos, objetos, imagens fotográficas, músicas, lugares, sabores, cheiros) e compreendendo melhor o valor do documento na vida local, passando assim a engendrar novas maneiras de recuperá-lo e conservá-lo.

Esse mergulhar conjunto e compartilhado no passado nos faz emergir mais conscientes quanto aos problemas contemporâneos da vida da comunidade estudada e geralmente nos conduz naturalmente a ações conjuntas e politicamente conscientes visando sua superação.

Mas os estudos sobre a memória trazem também uma outra exigência. À semelhança de muitas novas áreas do conhecimento, eles exigem uma abordagem multidisciplinar. Para entendêla e ao seu funcionamento é preciso valer-se de subsídios de várias disciplinas, realizando uma in- tegração de conceitos elaborados em diferentes áreas do conhecimento.

Assim, como vimos, a memória pode ser, ao mesmo tempo, subjetiva ou individual (porque se refere a experiências únicas vivenciadas ao nível do indivíduo), mas também social, porque é coletiva (pois se baseia na cultura de um agrupamento social e em códigos que são aprendidos nos processos de socialização que se dão no âmago da sociedade). Só a Sociologia nos permite desvendar esses aspectos da memória.

Sabemos também que ela nunca se apresenta de maneira ordenada ou cronológica, pois funciona através de associações livres entre as vivências e fatos do passado. Necessitamos da Psicologia para compreender esse funcionamento da memória.

O processo de registro dos fatos vivenciados e selecionados como importantes ainda é pouco conhecido, sendo objeto de constantes investigações. Sabemos que ele se baseia nas sinapses (ligações eletro-químicas) que conectam o vivido experienciado pelos sentidos com a área cerebral onde se dará o seu registro. Só as ciências biológicas nos ajudam a compreender esse aspecto.

Vimos também que, antes que o registro se processe, um importantíssimo filtro seletivo atuará separando o que deve ser retido daquilo que será descartado, filtro esse fornecido pela cultura de uma dada sociedade.

São os signos da cultura desvendados pela Semiótica que nos permitem uma primeira penetração em tal processo que encerra certamente um forte sentido de poder.

Para entender como cultura é memória e memória pela cultura permite exercer um poder que transcende tanto a Política como a Filosofia, precisamos dos conhecimentos destas duas ciências fechando assim, por hora, a necessária multidisciplinaridade exigida pelo objeto memória.

As instituições-memória realizam a produção

\footnotetext{
${ }^{10}$ VON SIMSON, Olga R. de Moraes. Construindo a história recente de Jarinu através da memória compartilhada. In PARK, Margareth B. (org.). Memória em movimento na formação de professores: prosas e histórias. Campinas, São Paulo: Mercado de Letras, 2000.p. 9 a 12.
} 
racional e organizada de uma memória perdida, ao invés de se constituírem como depositários de uma memória vivida, a qual só pode existir nos grupos sociais que apresentam intensa vivência coletiva e forte identidade cultural.

Para compensar esse caráter racional e organizado que o trabalho com a memória das instituições-memória precisa necessariamente apresentar, caráter esse que as impediria de captar toda a riqueza cultural dos fatos sociais, pois, na verdade trabalhamos com objetos que os representam, torna-se indispensável não nos voltarmos para simples vestígios ou documentos isolados, mas elaborarmos conjuntos documentais que nos permitam captar a intencionalidade e o simbolis- mo do corpo social ao registrar seu passado.

Só dessa forma se pode contribuir para a construção da identidade de um corpo social, pois é fornecendo a ele conjuntos documentais racional e tecnicamente tratados e realizando uma boa divulgação desse material que tais instituições poderão bem realizar seu papel de guardiãs da memória.

Hoje, pela utilização do método biográfico na construção destes ricos conjuntos documentais, são muitas as versões captadas, a partir de diferentes atores sociais, o que nos permite relativizar posições, compreender o contexto político cultural do período e nuançar com vários tons de cinza um passado que não pode ser reconstruído somente em tons de branco e negro.

\section{REFERÊNCIAS BIBLIOGRÁFICAS}

BOSI, Ecléa. Memósria e sociedade: lembranças de velhos. São Paulo: T.A. Queiroz, 1979.

BRITO, Marilza E. Memória e cultura. Centro de Memória da Eletricidade no Brasil. Rio de Janeiro, 1989. (Caderno da Memória da Eletricidade: n. 1).

CASSIANO, Célia. Memórias itinerantes: um estudo sobre a recriação das Folias de Reis em Campinas. 1998. Dissertação (Mestrado em Multimeios) Instituto de Artes, Universidade Estadual de Campinas, Campinas, São Paulo.

FERREIRA, Jerusa Pires. Cultura é Memória. In: Revista da USP. São Paulo, 1995, n. 24, p.115 -120.

GIGLIO, Zula; VON SIMSON, Olga. A arte de recriar o passado: história oral e velhice bem sucedida. In: NERI, Anita L. Desenvolvimento e envelhecimento: perspectivas biológicas, psicológicas e sociológicas. Campinas, São Paulo: Papirus, 2001.

HALBWACHS, Maurice. A memoria coletiva. S. Paulo: Vértice/ Revista dos Tribunais, 1990.

NORA, Pierre. Les lieux de memoire. 1. La Republique. Paris: Gallimard, 1984.

VON SIMSON, Olga. Os desafios contemporâneos da história oral. Campinas, Centro de Memória da Unicamp, 1997.

VON SIMSON, Olga R. de Moraes. Construindo a história recente de Jarinu através da memória compartilhada. In PARK, Margareth B. (org.). Memória em movimento na formação de professores: prosas e histórias. Campinas, São Paulo: Mercado de Letras, 2000.p. 9 a 12. 